Pedagogía y Saberes No. 49

Universidad Pedagógica Nacional

Facultad de Educación. 2018, pp. 41-53

\section{Uma ideia de arquivo: contributos \\ para a pesquisa educacional ${ }^{*}$}

Artículo de investigación

Una idea de archivo: contribuciones

a la investigación educativa

An Idea of Archive: Contributions to Research in Education

Julio Groppa Aquino** Gisela Maria do Val***

Para citar este artículo:

Aquino, J. y Do Val, G. (2018). Uma ideia de arquivo: contributos para a pesquisa educacional. Pedagogía y Saberes, 49, 41-53.

* 0 presente artigo é fruto de reflexão dos autores acerca das modalidades investigativas desenvolvidas pelo Coletivo de pesquisadores sobre educação e relações de poder (COPERP-USP), junto à Faculdade de Educação da Universidade de São Paulo.

** Profesor de la Facultad de Educación de la Universidade de São Paulo. Doctor en Psicología escolar e investigador el Grupo COPERP-USP.

Correo electrónico: groppaq@usp.br

Código ORCID: http://orcid.org/0000-0020-7912-9303

*** Doctora en Educación e investigadora del Grupo COPERP-USP.

Correo electrónico: giselaval@usp.br

Código ORCID: http://orcid.org/0000-0001-8004-0130 


\section{Resumo}

Este ensaio, de caráter reflexivo, devota-se a explorar a potencialidade da noção de arquivo para os afazeres investigativos no campo educacional. Tendo como base a teorização foucaultiana e a de alguns de seus interlocutores ulteriores, o artigo propõe dois procedimentos investigativos complementares: o arquivamento e a arquivização. Ao final, formula-se um paralelo entre o teatro da memória, projeto renascentista de Giulio Camillo, e o gesto arquivístico na pesquisa educacional.

\section{Palavras-chave}

metodologia; fontes; arquivamento; Michel Foucault

\section{Resumen}

Este ensayo, de carácter reflexivo, se dedica a explorar la potencialidad de la noción de archivo para los quehaceres investigativos en el campo educativo. Con base en las formulaciones foucaultianas y la de algunos de sus interlocutores posteriores, el artículo propone dos procedimientos investigativos complementarios: el archivamiento y la archivización. Al final, se formula un paralelo entre el teatro de la memoria, proyecto renacentista de Giulio Camillo, y el gesto archivístico en la investigación educativa.

\section{Palabras clave}

metodología; fuentes; archivamiento; Michel Foucault

\section{Abstract}

This reflection essay explores the potentiality of the notion of archive for research tasks in the field of education. Based on the Foucault's theories and that of some of his subsequent interlocutors, the paper proposes two complementary research procedures: archiving and archivization. At the end, a parallel is drawn between the theater of memory, the Renaissance project of Giulio Camillo, and the archival gesture in educational research.

\section{Keywords}

methodology; sources; archiving; Michel Foucault 


\section{Introdução}

Desde os esforços inaugurais de Gouveia (1971, 1976), o debate acerca da pesquisa educacional realizada no Brasil vem fomentando julgamentos marcadamente depreciativos. Por exemplo, em um dos textos-chave da discussão, Mello (1983) aponta dois movimentos associados naquilo que vinha, até então, sendo praticado sob o manto da investigação no campo educacional: a pobreza teórica e a inconsequência metodológica.

Sobre a primeira, temos que "a volubilidade, o estrangeirismo e o modismo temático da pesquisa educacional decorrem principalmente da inexistência de esquemas teóricos interpretativos consistentes a respeito da natureza do seu objeto, ou seja, da natureza da própria educação" (p. 68). Tratar-se-ia, pois, do efeito da importação desmesurada de modelos explicativos exógenos ao campo, sem atentar para a especificidade e, ao mesmo tempo, a complexidade deste. No segundo caso, "grande parte de nossas pesquisas se realizam segundo pressupostos teóricos, metodológicos, filosóficos e epistemológicos que ficam subentendidos e dos quais, às vezes, nem mesmo o pesquisador tem consciência" (p.69).

Também Warde (1990), ao relatar um estudo sobre a produção discente de programas de pós-graduação no país dos anos 1980, é taxativa: "Lamentavelmente, a grande maioria das dissertações não consiste em trabalho de pesquisa. [...] Assim, constato um duplo movimento: o estreitamento dos temas e a lassidão do método" (p.73).

Diagnóstico análogo é oferecido duas décadas depois por Gatti (2011), a pesquisadora mais assídua do tema. Para ela, o que avulta nas pesquisas é sua fragilidade quanto aos "meandros filosóficos, teóricos, técnicos e metodológicos da abordagem escolhida" (p. 75). Continua a pesquisadora:

Exercitar certa cobrança com mais clareza conceitual não tem sido propriamente uma preocupação na área. [...] Como campo que trabalha, também, pela apropriação teórica do produzido em outros campos (a filosofia, a sociologia, a antropologia, a linguística etc.) a questão conceitual e de posição epistêmica torna-se problema central. No entanto, nem sempre as fontes de referência originais têm seu campo conceitual tratado com adequação, pertinência e fineza teórica. (Gatti, 2012, pp. 18-19).

Como se pode observar, a inconsistência e, no limite, a displicência dos estudos parecem constituir dois pontos neurálgicos da "jovem pesquisa brasileira", assim como a reputou André (2006) ao perspectivar os movimentos que a constituíram historicamente. E, novamente, o diagnóstico se repete: "certa dispersão temática nos trabalhos, dependência excessiva de autores estrangeiros e fragilidade metodológica" (p. 22).

Talvez a acusação mais contundente seja aquela a cargo de Alves (1992), ao formular um elenco dos modos como comumente eram, então, realizadas as revisões da literatura nas teses e dissertações da área. 0 tom caricatural da descrição assume feições admoestatórias: trata-se daquilo que deveria ser evitado a todo custo. 13 são os tipos inesquecíveis de revisões, cada qual comportando um traço de incorreção: summa; arqueológico; patchwork; suspense; rococó; caderno B; coquetel teórico; apêndice inútil; monástico; cronista social; colonizado $\mathrm{X}$ xenófobo; off the records; ventríloquo. Destinadas, segundo a autora, a acumular mofo nos confins das bibliotecas universitárias, as produções, quando associadas a tais tipos, não passariam de "textos repetitivos, rebuscados, desnecessariamente longos ou vazios" (p. 58).

Tal cenário agrava-se quando entram em cena os tipos de análise efetuados. Nosella (2010), ao oferecer um balanço da produção dos programas de pós-graduação no país, destaca uma característica recorrente da pesquisa na área:

Frequentemente, há justaposição entre o referencial
teórico proclamado e o posto em prática, isto é, falta
organicidade entre o referencial teórico e os dados
empíricos coletados. Assim, na consideração dos as-
pectos empíricos, indispensável etapa do processo
de investigação, escapa o movimento real da his-
tória, que às vezes foi exposto como independente
da materialidade dos aspectos singulares, ou seja,
o ponto mais delicado da questão teórica é orga-
nizar os dados empíricos, para que deles emerja o
sentido do todo. Mas, para organizar esses dados, é
preciso possuir uma linha, uma direção, uma ideia
geral que costure os fragmentos da existência e da
história. (p. 180).

Tal embaraço procedimental, segundo boa parte de seus analistas, parece sobejar na pesquisa educacional contemporânea, redundando em leituras reducionistas do e sobre o presente educacional, a ecoar os crivos de inteligibilidade já em uso nas e pelas próprias práticas. Daí o risco de a pesquisa em educação se reduzir a um approach jornalístico, isto é, a uma mera reposição das informações obtidas junto às fontes empíricas eleitas -independentemente do recurso teórico ali ativado, aliás-ou, mutatis mutandis, ocasião de justaposição selvagem de determinadas palavras de ordem conceituais sobre tais fontes. 
Nesse sentido, Gatti (2006, p. 26) aconselha:

É preciso sair do nível do recolhimento de informações superficiais ou de senso comum, sair da "opinionatria", e buscar, com método, uma compreensão que ultrapasse nosso entendimento imediato, elaborando um conhecimento que desvende processos obscuros, subjacentes, um conhecimento que lance luz sobre fenômenos, sobre uma questão, segundo algum referencial.

Se, por um lado, a proliferação e a diversificação das pesquisas, nas últimas décadas, são signos inequívocos de fecundidade, por outro, não se pode franquear de antemão nenhum tipo de estabilidade quanto aos tipos de problema nem aos recortes conceituais empregados nas pesquisas, quanto tomadas em conjunto. A questão se torna ainda mais aguda quando entram em cena as fontes usualmente eleitas e, sobretudo, seu manuseio analítico.

Mais especificamente, seria necessário reconhecer que estamos diante de uma franca diáspora dos domínios investigativos na seara educacional. Prova disso é a profusão discursiva atestada entre algumas obras devotadas a deslindar métodos possíveis para a, doravante, multifacetada pesquisa educacional. Nessa direção, destacam-se os trabalhos capitaneados por Ludke e André (1986), Fazenda (1989; 1992) e Pimenta, Guedin e Franco (2006), até os mais recentes de Silva e Valdemarin (2010) e Gamboa (2012), em que são ora apresentadas, ora debatidas as tendências investigativas mais assentadas no campo, respeitando-se sua heterogeneidade epistemológica.

Tendo em mente o fato de que a pesquisa educacional consistiria em uma prática marcadamente híbrida - ou interdisciplinar, como preferem alguns-, condicionada que é pela confluência de saberes e procedimentos oriundos de territórios discursivos nem sempre congruentes, sugerimos que qualquer perspectivação da investigação no campo educacional deveria apontar não para uma tal debilidade do que ali se constituiu, mas para uma ambiência condicionada por forças discursivas em disputa e, portanto, em permanente tensão.

É nessa chave de pensamento que se pode apreciar a iniciativa analítica de Azanha (1992), para quem a pesquisa educacional, quando reduzida a uma motivação seja praticista, seja denuncista, restaria assolada por imperativos doutrinários. No primeiro caso, os estudos embalados por uma crença cientificizante "apenas conseguem estabelecer conclusões tão triviais que são irrelevantes de qualquer ponto de vista e até mesmo do ponto de vista prático" (p. 22). No segundo, tratar-se-ia do resultado de um recorrente abstracionismo pedagógico, tido como "o processo de deturpação ou escamoteamento do real pela via -ingênua ou astuciosa- da discussão abstrata transvestida de discussão teórica" (p.43).

0 diagnóstico de Azanha, mais afeito a uma mirada de teor contextualista em direção ao que se produziu no país até a década de 1990, parece-nos estratégico para perspectivar a situação contemporânea da pesquisa educacional, uma vez que o autor ultrapassa a crítica academicista, se se pode dizê-lo assim, apontando para forças discursivas nada débeis, particularmente aquelas capitaneadas pelas denominadas teorias críticas, obstinadas no combate aos efeitos deletérios da ordem político-econômica sobre as práticas educacionais, bem como na reconquista das práticas segundo uma exortação salvacionista.

Admite-se, pois, que, no rastro desse torvelinho de forças teóricas conflitantes se deu a emergência das pesquisas pós-críticas em educação a partir de meados dos anos 1990, as quais, segundo Paraíso (2004, p. 295),

\begin{abstract}
têm contribuído para a conexão de campos, para o desbloqueio de conteúdos, para a proliferação de formas e para o contágio de saberes minoritários. Os sentidos são multiplicados, os conhecimentos expandidos, os espaços de criação e invenção povoados. Elas têm-se posicionado contra a fixidez de significados, de narrativas, de valores, de classificações, de subjetividades, de verdades. Sua força tem sido grande, já que desarruma muito do já pensado na educação e mostra a importância de significar de outro modo, de criar, produzir, multiplicar e proliferar nesseterreno.
\end{abstract}

Empenhadas em oferecer subsídios para os fazeres investigativos doravante desvencilhados seja dos ditames cientificistas/desenvolvimentistas, seja dos ideais humanistas/progressistas, algumas obras coletivas vieram a público, tais como Costa (1996, 2002), Costa e Bujes (2005) e, mais recentemente, Meyer e Paraíso (2012).

Em que pese a potência presumida de tal tipo de teorização, temos chamado a atenção (Aquino, 2013), no caso específico da pesquisa foucaultiana, para uma espécie de fagocitose operativa do legado do pensador, a qual inclui desde usos meramente instrumentais até evocações apologéticas, redundando em apropriações hermeneutizantes de seu pensamento e, por extensão, na captura do próprio Foucault na função autor (Foucault, 2013c).

Mediante tal quadro conjuntural, desponta a potencialidade da ideia de $\operatorname{arquivo}^{1}$ e, mais

1 O emprego da expressão ideia de, aqui, emula explicitamente aquela empregada por Azanha (1992). 
especificamente, a de arquivamento/arquivização como procedimento investigativo para a pesquisa educacional - para além daquela de matriz foucaultiana. É o que aqui advogamos.

\section{Em torno da ideia de arquivo}

Em entrevista recente dedicada a explicitar o modus faciendi de seu último filme, intitulado No intenso agora, o documentarista João Moreira Salles traz à baila uma hipótese não de todo alheia ao que já havia se passado em Santiago, sua obra anterior, de 2007. Para o cineasta, a forma narrativa de seu filme atual teria derivado "quase como uma secreção do trabalho de montagem" (citado por Fonseca, 2017, s/p).

Esclareça-se que No intenso agora é composto pelo arquivo pessoal da mãe deSalles; arquivo constituído por imagens, por ela tomadas in loco, da Revolução Cultural chinesa, as quais são entremeadas por outras imagens: das lutas estudantis dos anos $1960 \mathrm{em}$ Paris, em Praga e no Rio de Janeiro. Afirma Salles: "A ideia deste filme não precedeu o trabalho de fazê-lo. Aconteceu o contrário. Foi só ao entrar na ilha de edição que o filme foi tomando forma" (citado por Fonseca, 2017, s/p).

Aqui, interessa-nos menos o viés argumentativo do filme e mais sua composição narrativa, uma vez que esta espelha o problema em foco no presente ensaio.

Como se pode deduzir de chofre, a lógica fílmica de No intenso agora resultou de uma experimentação baseada em fontes de segunda mão - uma operação arquivística, claro está-, tal como havia ocorrido com Santiago; este definido, segundo seu próprio subtítulo, como uma reflexão sobre o material bruto do depoimento memorialístico de Santiago Badariotti Merlo, ex-mordomo da família do diretor por três décadas, já octogenário. As sequências foram filmadas em 1992, abandonadas posteriormente e retomadas 13 anos depois. Trata-se, em suma, de um documentário sobre o documentário anterior, ou uma espécie de retomada crítica da primeira versão do filme.

A obra de Salles se nos figura de extrema valia, uma vez que é o trabalho de documentarizar, ${ }^{2}$ precisamente, que está em xeque - algo de todo coincidente, a nosso ver, com a problemática do manejo arquivístico na pesquisa acadêmica, uma vez que haverá invariavelmente uma metabolização narrativa dos acontecimentos pela intervenção analítica ou,

20 neologismo destina-se a diferenciar a ação convencional de documentar daquela operada pelos documentários fílmicos. Semelhante distinção ocorrerá, adiante, em relação ao termo arquivizar, de modo a distingui-lo do referente genérico arquivar, este circunscrito ao ato de recolher e classificar dados em um arquivo. como se costuma dizer, pela leitura do pesquisador. É a mão deste que operará uma ponte entre as duas instâncias antes desniveladas. E esta será sua obra.

Mais especificamente, documentarizar consiste em uma recomposição tradutória, e jamais uma transposição automática, de um conjunto de acontecimentos verídicos, isto é, que ocorreram historicamente, mas que são reapropriados inteiramente pela ação do documentarista — como o são, aliás, pelo historiador, por diferentes meios. Independentemente da veracidade ou mesmo da verossimilhança dos fatos examinados, a realidade aí em voga é, segundo Salles (2005, p. 63), "aquela construída pela imaginação autoral, uma imaginação que se manifesta tanto no momento da filmagem como no processo posterior de montagem". Trata-se, em suma, de uma operação recriadora da realidade documentada. Uma realidade doravante imaginada.

Ainda, no que concerne a No intenso agora, outra proposição axial desponta: a relação do presente com a verdade histórica. 0 documentário focaliza o maio de 68 francês, mas o faz sem a pretensão de se somar às fileiras narrativas já constituídas. Afirma Salles:

Não sou historiador e nem vivi o período. [...] Não
sei bem o que é o passado simbólico, mas se ele for
esse amálgama de mitos que o tempo fez chegar até
nós, então confesso que tenho interesse em oferecer
contranarrativas que possam devolver vitalidade a
uma história que, ao menos em parte, está cristali-
zada em nossa cabeça. Tirar as estátuas do pedestal
às vezes é bacana. (citado por Fonseca, 2017,s/p).

As noções de contranarrativa, imaginaçãoe, sobretudo, a de montagem, aqui em uso, remetem-nos imediatamente à tematização do trabalho arquivístico, tal como formulada por Michel Foucault (1997, 2006b, 2006d, 2008a, 2010b, 2013a, 2014a) e retomada por alguns de seus interlocutores teóricos, como Arlette Farge (2002, 2005, 2009), Georges Didi- Huberman (2012, 2013, 2016) e Philippe Artières $(1998,2006$, 2011a, 2011b, 2014).

Antes de tal exame teórico, cumpre-nos ponderar que a noção de arquivo comporta uma acentuada polissemia. Segundo a arquivologia, o termo refere-se a um domínio receptor que agrupa conjuntos de documentos de caráter pessoal e/ou institucional, reunidos segundo sua origem e função, assim também como os textos que tal domínio abriga (Bellotto, 2006).

Para tal campo, o arquivo, sempre ligado à noção de patrimônio, de construção de identidades sociais e de fortalecimento dos mecanismos de memória, pode ser considerado tanto a instituição de guarda dos documentos quanto o conjunto de textos selecionados, 
organizados e preservados segundo determinada lógica veridictiva. Segundo Castro (2008, p. 28), “o documento, portanto, não preexiste ao arquivo: um determinado artefato se constitui em documento na medida em que é associado por diferentes pessoas, a uma série de concepções de valor, memória e passado que o levam a ser preservado".

Partindo da premissa de que há uma dupla constituição entre documento e arquivo, este poderia ser denotado como uma construção social que, na opinião de Schwarts e Cook (2004, p. 16), estaria relacionada à "manutenção do poder, ao controle daquilo que é - e será- conhecido sobre o passado e ao poder da lembrança sobre o esquecimento". Trata-se, assim, do

poder para registrar certos eventos e ideias e não outros, poder para nomear, rotular e ordenar registros de acordo com as necessidades de negócios, governos e pessoas, poder para preservar e mediar o arquivo, poder sobre o acesso, poder sobre os direitos e liberdades individuais, sobre a memória coletiva e a identidade nacional. (p. 18).

Além de se tratar de uma construção sócio-histórica específica, o conjunto de documentos preservados carregaria, em última instância, uma aura questionável de legitimidade. Delmas (2010) acrescenta outro atributo ao arquivo, afirmando que este estaria obrigatoriamente ligado a uma ação - seja de uma pessoa, seja de uma instituição. Assim, para o autor, o "arquivo é resultado de uma ação passada que se pretende guardar, ao longo do tempo" (p. 61). Os documentos de um arquivo guardariam decisões, atos e informações, sendo, ao mesmo tempo, "instrumento de uma ação e o registro da mesma" (p. 130). Ainda, Delmas esclarece que as funções primordiais do arquivo seriam "provar, lembrar, entender e comunicar" (p. 142). Em resumo, o arquivo englobaria funções como defender direitos, lembrar a experiência pregressa para que seja possível agir, conhecer o que os antigos fizeram e descobriram, bem como identificar-se, a fim de construir uma existência promovendo relações por meio das quais os sujeitos possam se comunicar entre si.

A reboque das definições aqui evocadas, $\mathrm{o}$ arquivo teria o condão de constituir ou, ao contrário, extinguir atos, dizeres e comportamentos pregressos. Ou seja, um instrumento potente da forja histórica, tanto no que se refere à composição de determinado passado, quanto no que diz respeito à invenção do próprio presente.

Embrenhando-se na formulação de Foucault sobre o tema, pode-se dizer que, para ele, o arquivo é e o arquivo $f a z$, como bem explicou em uma entrevista de 1969:
Por arquivo, entendo o conjunto de discursos efetivamente pronunciados: e esse conjunto é considerado não somente como um conjunto de acontecimentos que teriam ocorrido uma vez por todas e que permaneceriam em suspenso, nos limbos ou no purgatório da história, mas também como um conjunto que continua a funcionar, a se transformar através da história, possibilitando o surgimento de outros discursos. (Foucault, 2008b, p. 145).

Mais do que a soma dos textos conservados por uma cultura como vestígios memoráveis do passado, testemunhos exemplares da história, conjunto de traços que, de algum modo, sobreviveram ao tempo, entesourados pelas instituições que registram e conservam aquilo que se quer guardar às gerações vindouras, ou mesmo instrumento de manipulação em favor de alguns, o arquivo, para o pensador francês, pode ser descrito sumariamente como a "lei do que pode ser dito" (p. 149).

Trata-se, assim, do conjunto de disposições que regem, em dada época e para determinada sociedade, os limites do dizível e, por extensão, os contornos cambiantes da memória coletiva, instaurando um movimento de apropriação e reativação incessantes de determinados enunciados. Assim, o arquivo caracteriza-se fundamentalmente por sua produtividade veridictiva, isto é, a delimitação não apenas das fronteiras entre o verdadeiro e do falso, mas também daquelas do pensável e do impensável em certo espaço-tempo histórico.

Ainda para Foucault, o princípio organizador do arquivo - os meios de circulação, de difusão, de uso e de reprodução, ou seja, tudo o que ele faculta quanto o que tolhe- descreve um âmbito que excede por completo a massa documental per se, tendo em mente que "o século XIX inventou a conservação documental absoluta: criou arquivos e a biblioteca, um fundo de linguagem estagnante que só existe para ser redescoberto por si mesmo no seu ser bruto" (Foucault, 2013b, p. 187).

Pode-se dizer que a sistematização textual, em sua própria enunciabilidade, define o arquivo. Tal sistema de enunciados não é a soma de todos os textos, mas aquilo que faz com que tantas coisas ditas tenham surgido não apenas a reboque das leis do pensamento ou do jogo das circunstâncias. Antes, elas perduram graças a todo um jogo de relações e de regularidades específicas que caracterizam particularmente o nível discursivo. "O 'arquivo' aparece, então, como uma espécie de grande prática dos discursos, prática que tem suas regras, suas condições, seu funcionamento" (Foucault, 2014a, p. 52). 
Para o pensador, a análise dos discursos implica três princípios: o tratamento do discurso não como tema que o reanimaria, mas como um trabalho de descrição de uma disposição própria; a busca não das leis de construção do discurso, mas de suas condições de existência, ou seja, não do espírito que lá habitaria, mas do campo prático no qual ele se desdobra; por fim, a análise propriamente do arquivo, de modo que se possa operar uma história das práticas discursivas a partir das relações específicas articuladas a outras práticas.

Procedendo dessa maneira, vislumbra-se o arquivo na esteira de uma recomposição infinita. Por um lado, ele é "[...] a massa das coisas ditas em uma cultura, conservadas, valorizadas, reutilizadas, repetidas e transformadas. Em resumo, toda essa massa verbal que foi fabricada pelos homens" (Foucault, 2014a, p. 52). Por outro, ele também é a apropriação possível de tal matéria nas coordenadas do presente histórico, já que atravessada por uma problematização que define a composição de um corpus próprio correspondente a indagações específicas dirigidas a tal massa verbal.Um mesmo arquivo possibilita, portanto, várias configurações, a depender dos problemas e das grades de leitura do pesquisador que o toma.

0 tipo de análise produzida por meio de tais procedimentos diferencia-se das abordagens que tratam os documentos como textos portadores de significações a serem decifradas ou reveladas, ou mesmo de linhas de força a vetorizar intenções supostamente recônditas e alheias a quem sobre elas se debruça. No momento em que a leitura do arquivo conforma-se por essa ação de desnaturalização de supostas significações latentes ou de interesses intervenientes, segundo uma motivação que desloca o olhar da busca de uma suposta origem, ele, o arquivo, começa a produzir ruídos.

O pesquisador passa a operar, então, como um "remontador de tempos perdidos - perdidos, mas eficientes até a nossa mais íntima contemporaneidade" (Didi-Huberman, 2013, p. 245). 0 trabalho arquivístico, nessas bases, implica uma investida arqueológica sob um olhar genealógico, capaz de abrigar "os lugares de confronto a partir dos quais o nosso presente foi urdido" (Leme, 2011, p. 99). Na esteira de tal investida é necessário estabelecer diálogos entre fontes múltiplas e heterogêneas, a fim de que se evidenciem descontinuidades e regularidades, sempre com vistas a um endereçamento crítico em relação àquilo que, no presente, aspira algum tipo de naturalização. Trata-se, enfim, de flagrar a arbitrariedade das certezas em voga, sempre tendo em mente que o "arquivo não diz a verdade, mas ele diz da verdade" (Farge, 2009, p. 35).
Para Farge, o arquivo é o território fundamental das narrativas históricas: "uma brecha no tecido dos dias, a visão retraída de um fato inesperado" (p. 14). Insinuar-se nessa brecha temporal seria o passo primordial para a desconstrução de saberes hegemônicos, pois tal imersão desarmaria as certezas garantidas pelos discursos em circulação.

Não éóbvio operar dessa maneira, cremos. A imersão na singularidade de um arquivo pode evidenciar a fragilidade de uma metodologia e desmantelar as hipóteses de largada, pois o pesquisador opera "entre a paixão de recolhê-lo [o arquivo] inteiro, de oferecê-lo integralmente à leitura, de jogar com seu lado espetacular e com seu conteúdo ilimitado, e a razão que exige que ele seja habilmente questionado para adquirir sentido" (p.21).

Na companhia de Foucault e de seus interlocutores, o percurso de uma pesquisa fundamentada na ideia de arquivo distingue-se pela abordagem dos documentos e pelo tipo de manuseio que a eles se concede, sempre com vistas à forja da acontecimentalização (Foucault, 2006c). Nesse sentido, importa não a preocupação com uma suposta verdade definitiva contida nos documentos, mas, a partir destes, 0 estabelecimento de séries e a descrição das relações que sustentaram sua própria aparição no tempo, pois, como assevera Foucault (2008d, p. 73), "não estamos mais na verdade, mas na coerência dos discursos".

Foi por intermédio de um intenso trabalho arquivístico que Foucault analisou o discurso de determinadas épocas como um emaranhado de fatos e feitos que funcionaram em certo período e em certo local e que continuaram a se transformar no decorrer do tempo, possibilitando o surgimento de outros discursos. Foi por meio de uma investida precisamente arqueogenealógica, fundada sobre o efetivamente dito/visto, que Foucault reordenou certas problematizações de seu tempo, as quais figuravam como focos de experiência (Foucault, 2010a). Como bem explicita o pensador, "por meio do pequeno gesto que consiste em deslocar o olhar, ele torna visível o que é visível, faz aparecer o que está tão próximo, tão intimamente ligado a nós que, por isso mesmo, não o vemos" (Foucault, 2011a, p. 246).

A fim de operar nessa chave teórico-metodológica, é necessário enveredar pelo arquivo sem realizar interpretação dos textos selecionados, sem vasculhar por detrás ou além deles em busca de um sentido latente ou perdido, enfim, sem tentar legitimá-los ou os invalidar. Isso porque a peleja analítica não se esgota nos documentos, embora deles não prescinda. Em outra direção, atua-se com o objetivo de mapear a concretude da superfície dos ditos/vistos como 
enunciados que foram passíveis de registro, mapeando suas conexões estratégicas, suas emergências, suas descontinuidades e seus tempos de duração.

Para tanto, é preciso desentranhar os documentos de sua historicidade estanque, entendendo-os precisamente como resultado de relações de força, ou seja, como o entrelaçamento das dinâmicas imanentes à sua materialização. Dito de outro modo, trata-se do espectro das respostas peremptórias e, tão logo, superadas que os antepassados foram capazes de formular mediante determinadas urgências de seu tempo. Trocando em miúdos, o arquivo materializa a dramaturgia ético-política que margeia e, ao mesmo tempo, suporta a marcha do tempo emparedada nos documentos. Daí que a tarefa analítica implica fazer os documentos falar não o que já dizem, mas como o dizem, conforme propõe Farge (2009).

A própria rotina investigativa de Foucault talvez seja um bom exemplo de tal tipo de envergadura analítica. Ele chegava à Biblioteca Nacional da França no horário de sua abertura e só a deixava no final do dia. Metódico, copiava trechos dos livros e dos documentos que utilizava. Sua coleção de excertos recolhidos durante a vida era imensa, composta de fragmentos que constituíam rascunhos de ideias, as quais, posteriormente, davam origem a seus livros e aulas. Artières (2014, p.137) assim descreve o trabalho de Foucault: "Era nos arquivos, no meio de maços de papéis, no fundo das bibliotecas que Foucault tinha feito a experiência de seu próprio pensamento". Daí sua conclusão certeira: o "ponto de fuga de sua filosofia era, portanto, o arquivo" (p.137).

Também Machado (2017, p. 65) revela algo inusitado acerca do procedimento foucaultiano no que concerne ao tipo de manufatura arquivística que lhe era característica:

[Foucault] Era homem de passar o dia inteiro na Bibliothèque Nacionale lendo textos que ninguém mais lia. Manuseava, às vezes, dez, vinte livros por dia, ou até mais. Certa vez me disse: "Quase não leio. Ler pelo prazer de ler, quase não faço mais isso. $\mathrm{Na}$ Nationale eu não leio; eu procuro".

Escarafunchar os arquivos, suas fulgurações, seus acidentes, seus pontos de virada: eis a gana de Foucault. Apenas um gesto, por meio do qual se faz possível concentrar-se em "pequenos fatos verdadeiros contra as grandes ideias vagas; a poeira desafiando a nuvem" (Foucault, 2006a, p. 324).

0 arquivo como poeira do tempo, em oposição diametral à jactância de metanarrativas impolutas.

\section{Arquivamento e arquivização}

A evocação anterior do fazer cinematográfico, neste ensaio, não foi fortuita. Isso porque se trata de uma prática que guarda ressonâncias diretas com o trabalho arquivístico, assim como o viemos concebendo até o momento, uma vez que aí se pode vislumbrar a existência de dois procedimentos equivalentes àqueles apontados por Salles. Designemo-los arquivamento e arquivização, tendo em mente que a obstinação documentária está para o primeiro procedimento do mesmo modo que a imaginação recriadora está para o segundo.

0 arquivamento é oportunizado por uma nítida inquietação acerca de um tema-problema investigativo, propulsora de uma imersão vertical na densidade e na dispersão de diferentes fontes correlatas (desde aquelas molares até as tópicas, laterais, adventícias etc.) com as quais o pesquisador se defronta em sua lida, o que requer o apego incondicional a "um grande número de materiais acumulados, paciência. [...] Em suma, uma certa obstinação na erudição" (Foucault, 2008c, p. 260).

Em outra passagem, Foucault é ainda mais explícito quanto ao tipo de disposição implicada no trabalho arquivístico nesses moldes. Vale a pena recuperá-la na íntegra:

\footnotetext{
Que o trabalho que lhes apresentei tenha tido esse aspecto ao mesmo tempo fragmentário, repetitivo e descontínuo, corresponderia bem a algo que se poderia chamar uma "preguiça febril", isto é, a que afeta de forma característica os apaixonados por bibliotecas, documentos, referências, escritas empoeiradas, textos que, apenas impressos, ficam trancados e dormem em seguida sobre estantes das quais só serão retirados alguns séculos mais tarde. Tudo isso conviria à inércia atarefada daqueles que professam um saber para nada, uma espécie desaber suntuário, uma riqueza de arrivista cujos sinais exteriores, como vocês sabem, se encontram dispostos no rodapé das páginas. Isso conviria a todos aqueles que se sentem solidários com uma das sociedades secretas provavelmente das mais antigas, e uma das características, também, do Ocidente, uma dessas sociedades secretas estranhamente indestrutíveis, que me parecem desconhecidas na Antiguidade e que se formaram logo no cristianismo, na época dos primeiros conventos, provavelmente, nos confins das invasões, dos incêndios e das florestas, quero falar da grande, terna e calorosa franco-maçonaria da erudição inútil. (Foucault, 2014b, p. 282).
}

Como se pode observar, a índole investigativa de Foucault em nada se assemelha a uma vontade de erudição canônica, modus operandi dos intelectuais 
universais, portadores de uma consciência interpretativa prodigiosa e engajada dos supostos mistérios do mundo (Foucault, 2011b). Na contramão do sonho cientificizante e, no limite, pastoral aí embutido, Foucault advoga em favor de um modo de endereçamento perdulário aos saberes constituídos; endereçamento que se dá antes pelos lapsos intervalares de tais saberes do que por seu encadeamento cumulativo, entendendo tais saberes como suportes de práticas específicas, bem como dos modos de subjetivação a elas conexos.

Tal como Didi-Huberman (2012, pp. 210-211) afirma,

cada vez que tentamos construir uma interpretação histórica - ou uma "arqueologia" no sentido de Michel Foucault-, devemos ter cuidado de não identificar o arquivo do qual dispomos, por muito proliferante que seja, com os feitos e gestos de um mundo do qual não nos entrega mais que alguns vestígios. 0 próprio do arquivo é a lacuna, sua natureza lacunar.

0 arquivamento corresponde, portanto, à tarefa de reordenação transversal das fontes, por meio das (re)montagens das lacunas discursivas em torno de determinados problemas concretos abrigados no e pelo arquivo.

O processo de análise do material inicia-se a partir de uma problematização do presente para arguir o passado, tomando a história como um âmbito de rupturas e descontinuidades, no rastro do qual se poderia estimar a emergência de tais problemas como uma irrupção, uma cisão arbitrária, a inauguração de um valor. Nessa perspectiva, o trabalho de eleição e processamento dos documentos de uma época relativamente distante de nós torna-se crucial, pois apenas por meio de certa suspensão temporal torna-se viável conjecturar as sombras e os contornos que a intensidade luminosa do presente se esforça para obstaculizar.

Se é necessário admitir que o gesto da inquirição foucaultiana opera por e sobre problematizações já disponíveis na poeira do arquivo, será igualmente necessário admitir que o ato de investigar nada teria a ver com a revelação de determinados universais que repousariam imberbes nos documentos, mas com o ensejo de contranarrar, como quer Salles, as correlações descritivas que modulam os modos correntes de endereçamento a eles. Disse decorre uma recusa tanto do plano explicativo das representações/mentalidades, quanto do da história das ideias, abstendo-se, assim, da busca por uma essencialidade universal ou por uma lei única que regesse as conexões veridictivas ali em uso. $\mathrm{O}$ arquivo é, portanto, lastro e efeito de uma produção marcada por alguma extemporaneidade.

0 termo montagem define exatamente a operação do arquivamento: atividade avizinhada a um quebra-cabeça ou, em alguma medida, a um caleidoscópio. 0 processo inicia-se com o manuseio de um amplo conjunto de documentos e, em seguida, de classificações dos enunciados, a fim de que seja possível isolar peças-chave e elementos adjacentes, com vistas à proposição de um mapa dos discursos que foram possíveis em uma dada época e em um local específico. A mirada do pesquisador passa a funcionar, então, como uma bússola que permite destacar alguns pontos cegos enunciativos, traçar relações entre eles, delinear um leitmotiv analítico -o qual, na maior parte das vezes, diferencia-se da temática investigativa inicial, quando considerada de modo isolado ou autônomo. Ou melhor, no confronto com o arquivo, a tematização prolifera-se, desvia-se, miscigena-se.

Mediante tal dispersão, o arquivamento - diferentemente das postulações clássicas da historiografia, mais afeitas ao apego a um objeto cronologicamente delimitado- pode abarcar tanto fontes ditas menores quanto aquelas consideradas mais canônicas, bem como séries documentais mais, ou menos, extensas. Com Foucault, trata-se de se fazer uso de fontes múltiplas e heterogêneas, de modo a abrir espaço para uma aproximação indeterminada à problemática em pauta. Em suma, é o próprio arquivo que delimitará a marcha investigativa, e não o anseio explanatório do pesquisador. Trata-se apenas de deambular, sempre atento ao que se passa ao redor das coisas ditas/vistas.

Erige-se, assim, o segundo procedimento investigativo: a arquivização. Ainda com Didi-Huberman (2012, pp. 211-212, grifo do autor):

\begin{abstract}
Frequentemente, nos encontramos, portanto diante de um imenso e rizomático arquivo de imagens heterogêneas difícil de dominar, de organizar e de entender, precisamente porque seu labirinto é feito de intervalos e lacunas tanto como de coisas observáveis. Tentar fazer uma arqueologia sempreé arriscar-se a por, uns junto a outros, traços de coisas sobreviventes, necessariamente heterogêneas e anacrônicas, posto que vêm de lugares separados e de tempos desunidos por lacunas. Esse risco tem por nome imaginação e montagem.
\end{abstract}

A díade imaginação-montagem firma-se como a atitude fulcral no que concerne ao trato arquivístico das fontes; este sempre labiríntico, frise-se, e jamais em busca de relações de causa-efeito presumidas de antemão. Um exemplo inequívoco de tal procedimento encontra-se nos últimos cursos de Foucault 
no Collège de France, em que o pensador opera com o, digamos, arquivo greco-romano. Suas torções, os saltos, o voo cego, enfim, sobre as fontes resultam surpreendentes do ponto de vista metodológico.

A operação de arquivização assemelha-se analogicamente à composição de um thriller policial, na medida em que as evidências não estão ocultas, embora não sejam imediatamente aparentes às lentes daqueles que as observam. Ao contrário, a própria saturação da visibilidade de um conjunto de enunciados correntes é o que nos impediria de vislumbrar os jogos de veridicção/subjetivação em torno de determinados nexos cognitivos enraizados no presente.

A arquivização, portanto, oscila entre uma perscrutação de cunho serial e outra acontecimental. A série, como uma somatória de textos afins dispostos em um estrato específico, proporciona uma visão mais ampla das fontes, devendo seu recorte temporal ser abrangente o bastante para oferecer uma visão em escala da temática em pauta, concomitantemente à utilização de documentos tangenciais que ora fazem falar, ora singularizam o silêncio de outras séries. Por sua vez, o acontecimento é pensado não no sentido dos marcos, dos tratados, das batalhas, das revoluções etc., mas "como uma relação de forças que se inverte, um poder confiscado, um vocabulário retomado e voltado contra seus utilizadores, uma dominação que se enfraquece, se amplia e se envenena e uma outra que faz sua entrada, mascarada" (Foucault, 2008c, pp. 272-273).

Segundo Foucault (2011a, p. 233), o "acontecimento não é um segmento de tempo, é o ponto de interseção entre duas durações, duas velocidades". Assim, a série constitui a superfície documental sobre a qual a investigação incide, ao passo que o acontecimento fundamenta os cortes e os desvios necessários ao tratamento dos documentos propriamente. Ambos, série e acontecimento, consistem no terreno sobre o qual é possível estipular pontos de ruptura, laços de continuidade, falas singulares etc.

Todo o processo arquivístico de uma investigação conjuga, pois, movimentos que devem, a rigor, operar em sincronia: de um lado, o arquivamento de uma produção discursiva relativamente vasta que, ao longo de séries, possibilita a reconstituição de racionalidades responsáveis por definir os regimes de dizibilidade de um momento e de um espaço dados; de outro, a arquivização oportuniza o encontro não somente com os papéis inertes da história, mas com potências ativas, na qualidade de pontos de inflexão que mobilizam e produzem ressonâncias, dada sua capacidade de produzirem desvio. Como relembra Farge (2009, p. 35), "o que se vê são elementos da realidade que por sua aparição em determinado momento histórico produzem sentido. É sobre essa aparição que é preciso trabalhar".

Para tanto, é preciso operar um trabalho de (re) montagem do arquivo capaz de "mostrar os conflitos, os paradoxos, os choques recíprocos dos quais toda história é tecida" (Didi-Huberman, 2016, p. 1). Trata-se, assim, de se mover em direção à massa das coisas ditas/vistas à moda de uma maquinaria descontínua e em constante deslocamento. Com Foucault (2010c, pp. 10-11), mais uma vez:

Não interrogo os discursos sobre o que, silenciosa-
mente, querem dizer, mas sobre o fato e as condições
de sua aparição manifesta; não sobre os conteúdos
que podem encobrir, mas sobre as transformações
que efetuaram; não sobre o sentido que neles se
mantém como uma origem perpétua, mas sobre o
campo onde coexistem, permanecem e apagam-se.

Reputando e operando o trabalho arquivístico segundo tais moldes, eis que estaríamos no cerne da atitude investigativa foucaultiana: endereçamo-nos ao arquivo do mundo a fim de interrogá-lo e, na medida de nossas forças, reconstitui-lo ponto a ponto.

$\mathrm{O}$ arquivo, em suma, como um "encontro improvável entre matérias heterogêneas, assimétricas e, no limite, incomunicáveis" (Aquino, 2016, p. 189).

\section{O arquivo como invenção}

0 passado parece exercer um pronunciado fascínio sobre a cultura ocidental. Catalogar dizeres, preservar documentos, eternizar determinada história da verdade já eram preocupações das sociedades antigas. No entanto, foi com a Modernidade e, em específico, com o advento dos Estados-Nação que tal prática se adensou. A institucionalização de museus, bibliotecas e acervos de diferentes tipos - sejam eles públicos ou pessoais-são mostras de tal philia colecionista, a título de combate à degradação e ao desaparecimento daquilo que passou a ser tido como patrimônio histórico.

A construção da memória coletiva, em prol da produção e da preservação de certos saberes reputados como dignos de serem levados adiante, vem inspirando instituições e indivíduos a selecionar e conservar materiais de caráter bibliográfico, científico, artístico etc., prestigiando determinadas narrativas e, consequentemente, menosprezando outras. Destarte, a construção da memória social fundamentada em dados do passado consistiria em uma estratégia eficaz de governo dos homens.

Colombo (1991) faz referência a Giulio Camillo, um pensador do final do século XV e do início do XVI que 
concebeu um dito teatro da memória. Em outra obra afim, Almeida (2005) informa que o grande projeto do renascentista tinha como objetivo reunir e difundir a totalidade da sabedoria humana. Destinada a ser frequentada por duas pessoas a cada vez, a obra imaginada pelo italiano invertia os lugares dos participantes, de modo que o espectador ocuparia o palco, e os saberes, a plateia. Nessa perspectiva, Camillo legou L'idea del teatro, uma espécie de enciclopédia devotada à memória universal. Estruturado a partir de uma classificação específica dos saberes -filosofia, literatura, ciência, religiões e artes-, tal acervo constituiria o próprio objeto do teatro, com vistas a "ajudar a memória e propiciar ao praticante da Arte da Memória o seu domínio" (Almeida, 2005, p. 13).

Segundo um intrincado sistema de disposições espaciais, a plateia era dividida em sete pilares principais, identificados pelos sete Sefirot $^{3}$ da Cabala e por sete anjos. Depois, cada pilar era subdivido em mais sete, de maneira a compor 49 estações, as quais estavam relacionadas a sete planetas, aos seus respectivos deuses e a sete aproximações ao pensamento platônico.

[...] o teatro Camillo oferecia um itinerário para que o praticante aplicado de sua arte percorresse imagens e locais, textos e ideias, imagens e palavras que reverberariame levariam a outras mais, escondidas ou secretas, numa rede inesgotável de relações, alusões, significações. (Almeida, 2005, p. 14).

A relação entre os saberes e o espectador aproxima-se da definição de uma biblioteca: local de conservação e racionalização formado por conjuntos de peças que delineiam modos específicos de pensar o mundo, com suas verdades e práticas diligentemente organizadas. Por se tratar de uma instância de teor colecionista, a biblioteca reúne artificialmente matérias que são classificadas por temas, as quais possuem funções tanto culturais quanto científicas (Bellotto, 2006).

Contudo, a investida do pensador renascentista, adepto da alquimia, também pode ser aproximada de uma ideia despatrimonializante de arquivo, já que no seu teatro da memória são dispostos objetos e dizeres preservados como portadores de perguntas sobre a história das coisas, e não necessariamente como receptáculos de respostas. Isso porque os vestígios do passado, depositários de ações e discursos, não oferecem, em si mesmos, nenhum sentido apriorístico. A compreensão da trama que enreda tais vestígios só se torna possível por meio de um olhar

3 As emanações divinas, as quais formam a árvore da vida (Scholem, 1972). previamente adquirido. Aqueles objetos dispostos por Camillo, portanto, constituiriam uma memória conquanto houvesse um nexo que os descrevesse, interconectando-os.

A ideia da montagem novamente ganha corpo, agora enraizada em uma criação da Renascença italiana por um personagem produtor de um manejo arquivístico insólito, o qual se define exatamente pela capacidade de montar, desmontar e remontar os materiais ali dispostos, tornando possível o reconhecimento da dispersão dos elementos encontrados, do descompasso entre a duração e o devir, bem como, por fim, do embate perene entre permanência e instabilidade.

A seleção dos dados efetuada por Camillo, do mesmo modo que a intrincada ordenação por ele elaborada, é deveras solidária à acepção de arquivo que foi cultivada no presente ensaio. Na perspectiva foucaultiana, mais do que a materialidade, a função catalogadora e a lógica da seleção dos materiais selecionados, o que se destaca no arquivo são os embates concretos das forças vitais que reverberam para além do seu encerramento nos documentos; embates que têm o condão de nos interceptar de infinitas maneiras. 0 arquivo, portanto, como murmúrio perpétuo.

A idealização de Camillo faz despontar uma ideia de arquivo sem a ênfase na verdade carreada pelo afã documentador e sem a preocupação com uma sua autoridade supostamente legitimadora. Ao contrário, o arquivo, nessa direção, se aproxima de uma positividade liquefeita, sempre aberta, sempre por se refazer. Uma positividade autoperformadora, pois.

Na utopia do alquimista italiano, os protagonistas da trama trocam de lugar: o espectador permanece no palco, ouvindo, lendo e observando marcas, resíduos e vestígios de um passado imaginado, ou seja, os ruídos do arquivo por ele decifráveis. Provavelmente ele, o espectador, traçaria um caminho, delimitado por um interesse tópico ou por um problema circunstancial. Nesse percurso, atentaria para alguns textos e objetos, articulando-os a uma tênue rede de relações conexas às suas preocupações contemporâneas, e forjando, assim, um amálgama - frágil e irresoluto, decerto - entre os diversos objetos e dizeres à sua disposição. Tal (re)montagem do tempo consistiria, quiçá, em "um procedimento capaz de pôr em movimento novos espaços de pensamentos" (Didi-Huberman, 2013, p. 251).

0 sonho de um renascentista e o gesto procedimental de um pensador francês do século $\mathrm{xx}$ podem, mesmo com alguns séculos de distância, ser aproximados, propiciando um desses encontros 
improváveis com o próprio presente — também e sobretudo no âmbito da pesquisa educacional.

A atenção à noção geral de arquivo e, especificamente, às de arquivamento e arquivização permite, cremos, transformar ou, quiçá, superar a suspeita ora de labilidade, ora de negligência, ora, ainda, de descontrole que, em maior ou menor grau, persiste quando se trata de dimensionar as práticas investigativas aí levadas a cabo. Ademais, trata-se de lhes conferir uma potência de estranhamento e de reinvenção do próprio tempo. Em suma, uma chave-mestra para o labor investigativo, cuja efetividade é facultada apenas a partir do tipo de uso que se lhe dá, bem como do tipo de inquietação interrogante que ele pressupõe e exige.

\section{Referências}

Almeida, M. (2005). O teatro da memória de Giulio Camillo. Cotia, SP: Ateliê Editora, Campinas: EDUNICAMP.

Alves, A. (1992). A "revisão da bibliografia" em teses e dissertações: meus tipos inesquecíveis. Cadernos de pesquisa, 81, 53-60.

André, M. (2006). A jovem pesquisa educacional brasileira. Revista Diálogo Educacional, 6(19), 11-24.

Aquino, J. (2013). A difusão do pensamento de Michel Foucault na educação brasileira: um itinerário bibliográfico. Revista Brasileira de Educação, 18(53), 301-324.

Aquino, J. (2016). Não mais, mas ainda: experiência, arquivo, infância. Childhood \& Philosophy, 12(23), 179-200.

Artières, P. (1998). Arquivar a própria vida. Revista Estudos Históricos, 11(21), 9-38.

Artières, P. (2006). Entrelinhas: ler os arquivos de Michel Foucault. In: Scavone, L., Alvarez, M. C. \& Miskolci, R. (Orgs.). O legado de Foucault (pp. 21-19). São Paulo: EDUNESP.

Artières, P. (2011a). Arquivos do corpo, arquivo da biopolítica. Cadernos Brasileiros de Saúde Mental, 3(6), 92-211.

Artières, P. (2011b). Monumentos de papel: a propósito de novos usos sociais dos arquivos. Em Salomon, M. (Org.). Saber dos arquivos (pp. 99-110). Goiânia: Riochete.

Artières, P. (2014). A exatidão do arquivo. Em: P. Artières etal. Michel Foucault (pp. 137-141). Rio de Janeiro: Forense.

Azanha, J. (1992). Uma ideia de pesquisa educacional. São Paulo: EDUSP.

Bellotto, H. (2006). Arquivos permanentes: tratamento documental. Rio de Janeiro: FGV.

Castro, C. (2008). Pesquisando em arquivos. Rio de Janeiro: Jorge Zahar.
Colombo, F. (1991). Os arquivos imperfeitos: memória social e cultura eletrônica. São Paulo: Perspectiva.

Costa, M. (Org.). (1996). Caminhos investigativos: novos olhares na pesquisa em educação. Porto Alegre: Mediação.

Costa, M. (Org.). (2002). Caminhos investigativos II: outros modos de pensar e fazer pesquisa em educação. Rio de Janeiro: DP\&A.

Costa, M. e Bujes, M. (Orgs.). (2005). Caminhos investigativos III: riscos e possibilidades de pesquisar nas fronteiras. Rio de Janeiro: DP\&A.

Delmas, B. (2010). Arquivos para quê? Textos escolhidos. São Paulo: Instituto Fernando Henrique Cardoso.

Didi-Huberman, G. (2012). Quando as imagens tocam o real. Pós, 2(4), 204-219.

Didi-Huberman, G. (2013). Atlas ou a Gaia Ciência inquieta. Lisboa: KKYM + EAUM.

Didi-Huberman, G. (2016). Remontar, remontagem (do tempo). [Caderno de Leituras, n. 47]. Belo Horizonte: Chão da Feira.

Farge, A. (2002). Penser et définir l'événement en histoire. Terrain. Recuperado de: http://journals.openedition. org/terrain/1929

Farge, A. (2005). Quel bruit ferons-nous? Entretiens avec Jean-Christophe Marti. Paris: Les Prairies Ordinaires.

Farge, A. (2009). O sabor do arquivo. São Paulo: EDUSP.

Fazenda, I. (Org.). (1989). Metodologia da pesquisa educacional. São Paulo: Cortez.

Fazenda, I. (Org.). (1992). Novos enfoques da pesquisa educacional. São Paulo: Cortez.

Fonseca, R. (2017, 24 de abril). No Intenso Agora. “Hoje não há mais um projeto único capaz de organizar o entusiasmo coletivo", diz diretor. Omelete. Recuperado de https://omelete.uol.com. br/filmes/entrevista/no-intenso-agora-hoje-nao-ha-mais-um-projeto-unico-capaz-de-organizar-o-entusiasmo-coletivo-diz-diretor/.

Foucault, M. (1997). Arqueologia do saber. Rio de Janeiro: Forense Universitária.

Foucault, M. (2006a). A poeira e a nuvem. Em M. Foucault. Estratégia, poder-saber (pp. 323- 334). Rio de Janeiro: Forense Universitária.

Foucault, M. (2006b). Estratégia, poder-saber. Rio de Janeiro: Forense Universitária.

Foucault, M. (2006c). Mesa-redonda em 20 de maio de 1978. Em Foucault. M. Estratégia, poder-saber (pp. 335-351). Rio de Janeiro: Forense Universitária.

Foucault, M.(2006d). Microfísica do poder. Rio de Janeiro: Graal. 
Foucault, M. (2008a). Arqueologia das ciências e história dos sistemas de pensamento. Rio de Janeiro: Forense Universitária.

Foucault, M. (2008b). Michel Foucault explica seu último livro. Em M. Foucault. Arqueologia das ciências e história dos sistemas de pensamento (pp. 145-152). Rio de Janeiro: Forense Universitária.

Foucault, M. (2008c). Nietzsche, a genealogia, a história. Em Foucault, M. Arqueologia das ciências e história dos sistemas de pensamento (pp. 260-281). Rio de Janeiro: Forense Universitária.

Foucault, M. (2008d). Segurança, território, população. São Paulo: Martins Fontes.

Foucault, M. (2010a). O governo de si e dos outros. São Paulo: WMF Martins Fontes.

Foucault, M. (2010b). Repensar a política. Rio de Janeiro: Forense Universitária.

Foucault, M. (2010c). Resposta a uma questão. Em M. Foucault. Repensar a política (pp. 1- 24). Rio de Janeiro: Forense Universitária.

Foucault, M. (2011a). A cena da filosofia. Em M. Foucault. Arte, epistemologia, filosofia e história da medicina (pp. 222-247). Rio de Janeiro: Forense Universitária.

Foucault, M. (2011b). A função política do intelectual. Em M. Foucault. Arte, epistemologia, filosofia e história da medicina (pp. 213-219). Rio de Janeiro: Forense Universitária.

Foucault, M. (2013a). Estética: literatura e pintura, música e cinema. Rio de Janeiro: Forense Universitária.

Foucault, M. (2013b). O Mallarmé de J.P. Richard. Em M. Foucault. Estética: literatura e pintura, música e cinema (pp. 185-195). Rio de Janeiro: Forense Universitária.

Foucault, M. (2013c). 0 que é um autor? Em: M. Foucault. Estética: literatura epintura, música e cinema (pp. 268302). Rio de Janeiro: Forense Universitária.

Foucault, M. (2014a). O nascimento de um mundo. Em M. Foucault. Filosofia, diagnóstico do presente e verdade (pp. 51-54). Rio de Janeiro: Forense Universitária.

Foucault, M. (2014b). Aula de 7 de janeiro de 1976. Em M. Foucault. Filosofia, diagnóstico do presente e verdade (pp. 281-295). Rio de Janeiro: Forense Universitária.

Gamboa, S. (2012). Pesquisa em educação: métodos e epistemologias. Chapecó: Argos.

Gatti, B. (2006). Pesquisar em educação: considerações sobre alguns pontos-chave. Diálogo Educacional, 6(19), 25-35.
Gatti, B. (2011). Implicações e perspectivas da pesquisa educacional no Brasil contemporâneo. Cadernos de pesquisa, 113, 65-81.

Gatti, B. (2012). A construção metodológica da pesquisa em educação: desafios. Revista Brasileira de Política e Administração da Educação, 28(1), 13-34.

Gouveia, A. (1971). Pesquisa educacional no Brasil. Cadernos de Pesquisa, 1, 1-48.

Gouveia, A. (1976). Pesquisa em educação no Brasil: de 1970 para cá. Cadernos de Pesquisa, 19, 75-79.

Leme, J. (2011). Da significação ao acontecimento: Foucault e a genealogia da experiência. Em: H. Resende (Org.). Michel Foucault: transversais entre educação, filosofia e história (pp. 91-104). Belo Horizonte: Autêntica.

Ludke, M. e André, M. (1986). Pesquisa em educação: abordagens qualitativas. São Paulo: EPU.

Machado, R. (2017). Impressões de Michel Foucault. São Paulo: n-1 edições.

Mello, G. (1983). Pesquisa educacional no Brasil. Cadernos de Pesquisa, 46, 67-72.

Meyer, D. e Paraíso, M. (Orgs.). (2012). Metodologias de pesquisas pós-críticas em educação. Belo Horizonte: Mazza Edições.

Nosella, P. (2010). A pesquisa em educação: um balanço da produção dos programas de pós- graduação. Revista Brasileira de Educação, 15(43), 177-203.

Paraíso, M. (2004). Pesquisas pós-críticas em educação no Brasil: esboço de um mapa. Cadernos de Pesquisa, 34(122), 283-303.

Pimenta, S., Ghedin, E. e Franco, M. (Orgs.). (2006). Pesquisa em educação: alternativas investigativas com objetos complexos. São Paulo: Loyola.

Salles, J. (2005). A dificuldade do documentário. Em: J. S. Martins, C. Eckert. e S. C. Novaes (Orgs.). O imaginário e o poético nas ciências sociais (pp. 57-71). Bauru: EDUSC.

Scholem, G. (1972). A mística judaica. São Paulo: Perspectiva.

Schwartz, J. e Cook, T. (2004). Arquivos, documentos e poder: a construção da memória moderna. Registro: revista do Arquivo Nacional de Indaiatuba/Fundação Pró-memória, 3(5), 15-30.

Silva, M. e Valdemarin, V. (Orgs.). (2010). Pesquisa em educação: métodos e modos de fazer. São Paulo: Cultura Acadêmica.

Warde, M. (1990). O papel da pesquisa na pós-graduação em educação. Cadernos de Pesquisa, 73, 67-75. 


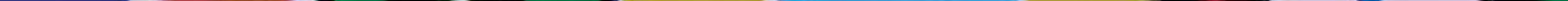

